\title{
Age Hardening and Thermal Stability of Al-Cu Alloy Processed by High-Pressure Torsion
}

\author{
Intan Fadhlina Mohamed ${ }^{1,2, *}$, Yosuke Yonenaga ${ }^{1}$, Seungwon Lee ${ }^{1,2}$, Kaveh Edalati ${ }^{1,2}$ \\ and Zenji Horita ${ }^{1,2}$ \\ ${ }^{1}$ Department of Materials Science and Engineering, Faculty of Engineering, \\ Kyushu University, Fukuoka 819-0395, Japan \\ ${ }^{2}$ WPI, International Institute for Carbon-Neutral Energy Research (WPI-I2CNER), \\ Kyushu University, Fukuoka 819-0395, Japan
}

An age-hardenable $\mathrm{Al}-4$ wt.\% $\mathrm{Cu}$ alloy is severely deformed using high-pressure torsion (HPT) to refine the microstructure to an average gain size of $\sim 210 \mathrm{~nm}$. High saturation hardness of $205 \mathrm{Hv}$ and high tensile strength of $820 \mathrm{MPa}$ are achieved after the HPT processing. It is shown that the strength of the HPT-processed alloy is further improved by natural aging at room temperature or by artificial aging at $353 \mathrm{~K}$. A peak hardness followed by softening appears within a few days after natural aging and within a few minutes after aging at $353 \mathrm{~K}$, suggesting the low thermal stability of the alloy. Quantitative evaluation of different strengthening mechanisms shows that the grain boundary hardening through the Hall-Petch relationship and the precipitation hardening through the Orowan relationship are dominant strengthening mechanisms.

Keywords: Severe plastic deformation (SPD); High-pressure torsion (HPT); Ultrafine-grained Materials (UFG); Precipitation hardening; Aluminum alloys.

*Corresponding author: Intan Fadhlina Mohamed

Tel/Fax: +81-92-802-2992, E-mail: intan@ zaiko6.zaiko.kyushu-u.ac.jp 


\section{Introduction}

High-pressure torsion (HPT) is a well-known severe plastic deformation (SPD) process and it is capable of refining the grain size to the submicrometer or nanometer range and consequently of enhancing the strength and hardness in most metallic materials [1-6]. In HPT process, a thin disc sample is compressed between two anvils under a high pressure and shear strain is concurrently introduced by rotating the anvils with respect to each other [1]. Since the earliest work by Bridgman in 1935 [1], it has been shown that the hardness and strength of materials evolve into saturation levels with straining [1-16], where hardness, strength, grain size and dislocation density remain unchanged with further increase in the shear strain. It is of particular scientific and industrial interest to find some strategies to improve the hardness and strength of HPT-processed materials above the saturation levels.

For ultrafine-grained (UFG) materials processed by HPT, besides the strengthening by grain refinement through the Hall-Petch relation [17,18], the strength can be improved by some other factors such as dislocation accumulation through the Bailey-Hirsch relationship [19], solid solution hardening through the Fleischer and Labusch relationships and precipitation hardening through the Orowan relationship [20,21]. It was shown that although the contribution of solid-solution hardening to the total strength of HPT-processed materials is less than $15 \%$, the solute atoms can significantly improve the strength because of their contribution to extra grain refinement [11]. Moreover, solute atoms can usually improve the 
thermal stability of the UFG materials [5]. Earlier studies showed that solute atoms can produce extra strengthening in UFG materials by formation of precipitates [22-27], although precipitation may occur heterogeneously because of formation of precipitates on dislocations and grain boundaries during aging [28-30].

The purpose of this research is to study the evolution of microstructure, mechanical properties and thermal stability in a precipitation-hardenable $\mathrm{Al}-\mathrm{Cu}$ alloy during HPT processing and after post-HPT aging. The contribution of different hardening mechanisms such as hardening by grain refinement, hardening by dislocation accumulation, solid solution hardening and precipitation hardening is investigated.

\section{Experimental materials and procedures}

The material used in this study was an $\mathrm{Al}-4$ wt.\% $\mathrm{Cu}(1.7$ atom\% $\mathrm{Cu})$ Alloy. The material was received in a form of an ingot with dimensions of $1.5 \times 10 \times 25 \mathrm{~cm}^{3}$. The ingot was homogenized at $793 \mathrm{~K}$ for $24 \mathrm{~h}$ in an air atmosphere and slowly cooled down in the furnace. Discs of $1 \mathrm{~mm}$ thickness and $10 \mathrm{~mm}$ diameter were cut from the homogenized ingot using a wire-cutting electric discharge machine (EDM). The discs were solution-treated at 823 $\mathrm{K}$ for $5 \mathrm{~h}$ in an argon atmosphere and immediately quenched into ice water.

Each disc was processed by HPT at room temperature (R.T.) under an applied pressure of $P=6 \mathrm{GPa}$ for $N=0.5,1$ and 5 turns at a rotation speed of $\omega=1 \mathrm{rpm}$. The thicknesses of 
discs were reduced from $1 \mathrm{~mm}$ to $\sim 0.8 \mathrm{~mm}$ during the HPT processing. The HPT-processed discs were stored at room temperature for up to 18 days to investigate their natural aging and thermal stability. Several discs were aged at $353 \mathrm{~K}$ in the air atmosphere for certain periods of time up to 5 days.

For each disc sample, Vickers microhardness was measured at 8 different radial directions, as illustrated in Fig. 1, by application of a load of $100 \mathrm{~g}$ for a dwell time of $15 \mathrm{~s}$.

For phase analyses, $3 \mathrm{~mm}$ discs were prepared from the edge of disc samples, as shown in Fig. 1. X-ray diffraction (XRD) analyses were performed on $3 \mathrm{~mm}$ discs using the $\mathrm{Cu} \mathrm{K} \alpha$ radiation at an accelerating voltage of $40 \mathrm{kV}$ and a current of $36 \mathrm{~mA}$ in a scanning step of $0.02^{\circ}$ and a scanning speed of $0.5 \% \mathrm{~min}$.

Tensile specimens having $1.5 \mathrm{~mm}$ gauge length, $0.7 \mathrm{~mm}$ width and $0.5 \mathrm{~mm}$ thickness were cut from the disc samples using EDM, as illustrated in Fig. 1. Tensile tests were carried out at room temperature with an initial strain rate of $2 \times 10^{-3} \mathrm{~s}^{-1}$.

For microstructural observations, the disc samples were punched to small discs with $3 \mathrm{~mm}$ diameters, as shown in Fig. 1, and further ground to a thickness of $0.12 \mathrm{~mm}$. The $3 \mathrm{~mm}$ discs were thinned using a twin-jet electrochemical polishing system using a solution of $20 \%$ $\mathrm{HNO}_{3}$ and $80 \% \mathrm{CH}_{3} \mathrm{OH}$ at a temperature of $260 \mathrm{~K}$ with an applied voltage of $12 \mathrm{~V}$. The microstructural examinations were performed using transmission electron microscopy (TEM) at an accelerating voltage of $200 \mathrm{kV}$. Selected-area electron diffraction (SAED) patterns were 
also taken from regions with $6.3 \mu \mathrm{m}$ diameter for each microstructural examination.

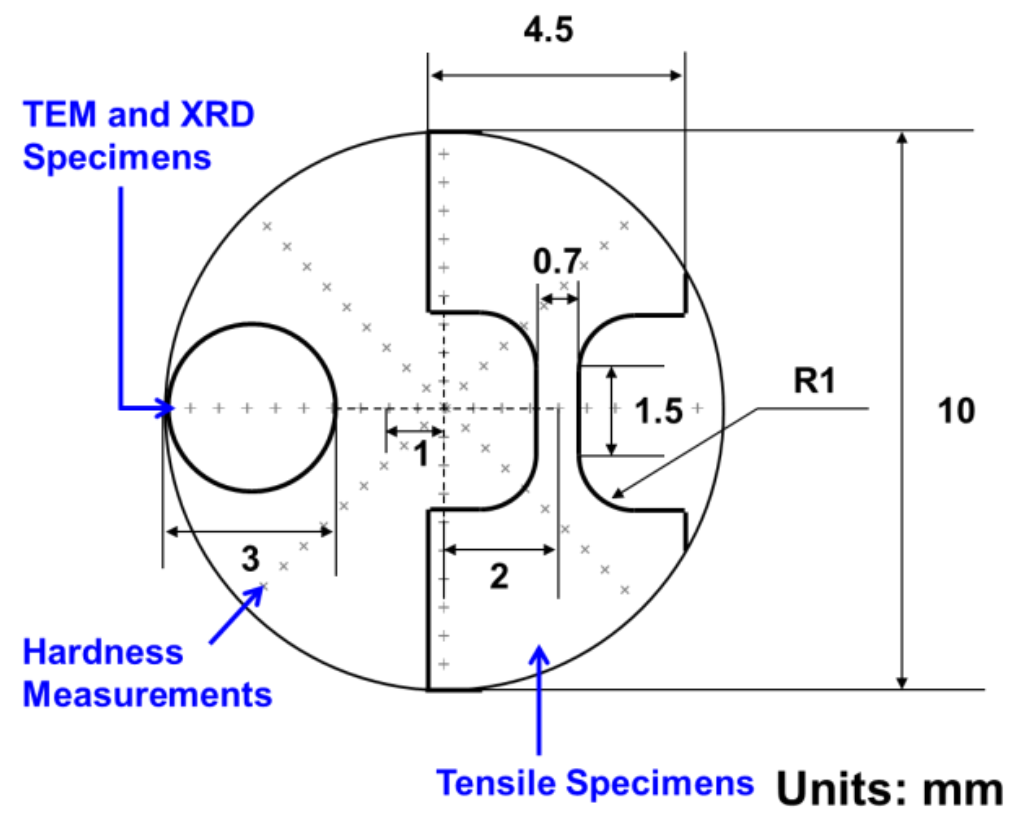

Figure 1 Schematic illustration of HPT disc and locations for hardness measurements, tensile specimen and TEM and XRD discs.

\section{Results}

\subsection{Mechanical properties after HPT}

The variations of Vickers microhardness are plotted in Fig. 2(a) against the distance from the center of discs after processing for $N=0.5,1$ and 5 turns. The lower dotted lines show the hardness levels for the homogenized and solution-treated samples. Microhardness increases with increasing the distance from the disc center as well as with increasing the numbers of turns, but the hardness tends to saturate to a steady state level of $210 \mathrm{Hv}$ at $\sim 1 \mathrm{~mm}$ from the disc center after 5 turns. All hardness levels after the HPT processing are drastically higher than those after the solution treatment. 
All microhardness values in Fig. 2(a) are plotted against the von Mises equivalent strain in Fig. 2(b). The von Mises equivalent strain, $\varepsilon$, was calculated by the following equation $[2,3]$ :

$$
\varepsilon=\frac{2 \pi r N}{\sqrt{3} t}
$$

where $r$ is the distance from the disc center, $N$ is the number of turns and $t$ is the thickness of disc. It is apparent that all the points laid essentially on a single curve regardless of the number of turns and distance from the disc center. It is noticeable that the saturation occurs at a well-defined equivalent strain beyond $\sim 30$ where the hardness remains constant with further straining. The hardness-strain behavior and the occurrence of steady state for the Al-Cu alloy is consistent with those reported earlier in numerous metallic materials [2-11] including low-purity $\mathrm{Al}$ (99\%) [13], but is different from the hardness behavior of high-purity $\mathrm{Al}$ (99.99\%, 99.999\%) which exhibits a hardness peak followed by softening at large strains [13-16]. 
(a)

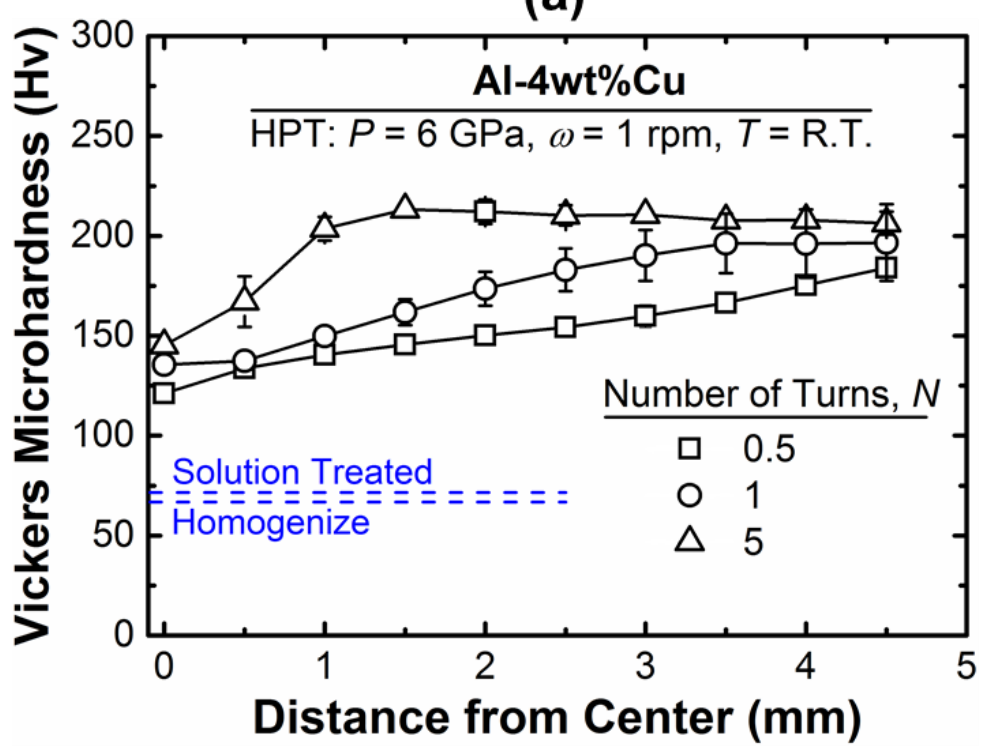

(b)

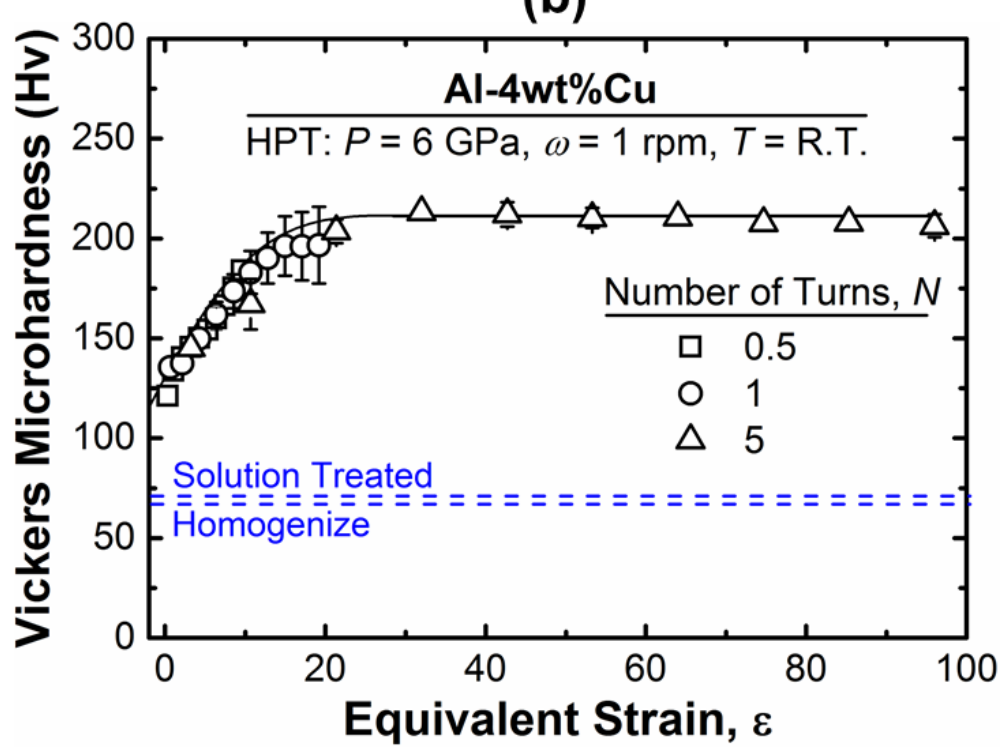

Figure 2 Vickers microhardness plotted against (a) distance from disc center and (b) equivalent strain for samples processed by HPT after various turns. 
Figure 3 shows the stress-strain curves after tensile testing conducted at room temperature with an initial strain rate of $2 \times 10^{-3} \mathrm{~s}^{-1}$ for the samples processed by HPT for various turns including the sample after solution treatment. The tensile strength significantly increases with increasing the numbers of turns and a maximum strength of $820 \mathrm{MPa}$ is achieved after 5 turns. The tensile ductility decreases significantly after the HPT processing, but the total elongation to failure remains appreciably high $(\sim 25 \%)$.

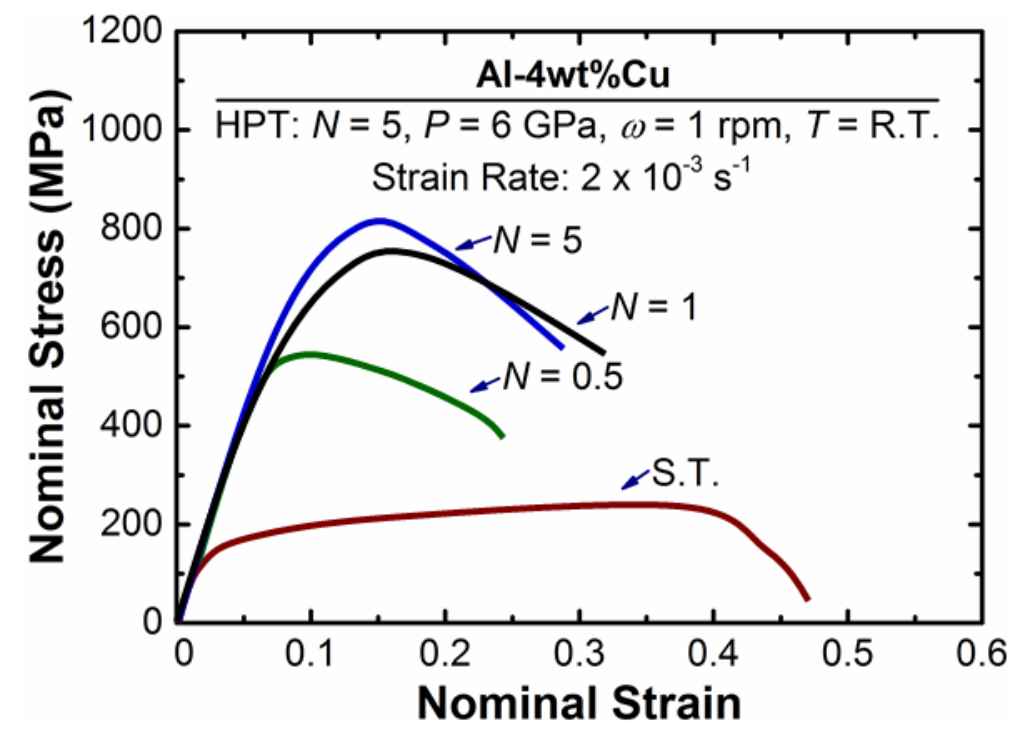

Figure 3 Nominal stress versus nominal strain curves for samples processed by HPT after various turns including solution-treated sample. 
Results of tensile testing are summarized more clearly in Fig. 4, where (a) ultimate tensile strength (UTS), (b) uniform elongation and total elongation to failure are plotted against the equivalent strain. The level of UTS increases abruptly at lower equivalent strain but thereafter, the increase is more gradual to level off at higher equivalent strain. This trend is almost similar to the hardness variation with straining as in Fig. 2(b). The total elongation to failure and uniform tensile ductility decrease abruptly after $N=0.5$ but they increase slightly and remain constant at higher equivalent strain. The variations of elongation against equivalent strain for the $\mathrm{Al}-\mathrm{Cu}$ alloy are similar to those reported for pure $\mathrm{Cu}$, in which a peak for minimum ductility was reported [31].

It should be noted that the tensile tests in this study were conducted at room temperature with the initial strain rate of $2 \times 10^{-3} \mathrm{~s}^{-1}$. It is expected that the tensile behavior should be almost the same at other strain rates below $1 \times 10^{-2} \mathrm{~s}^{-1}$ which it is possible to adopt in the present tensile testing system. The strain rate sensitivity reported in the literature [32-35] is sufficiently low at room temperature, despite some extents of the increase in the strain rate sensitivity through reduction in the grain size to the submicrometer levels [32-34]. Therefore, the flow stress remains almost little changed with respect to the strain rate. 
(a)

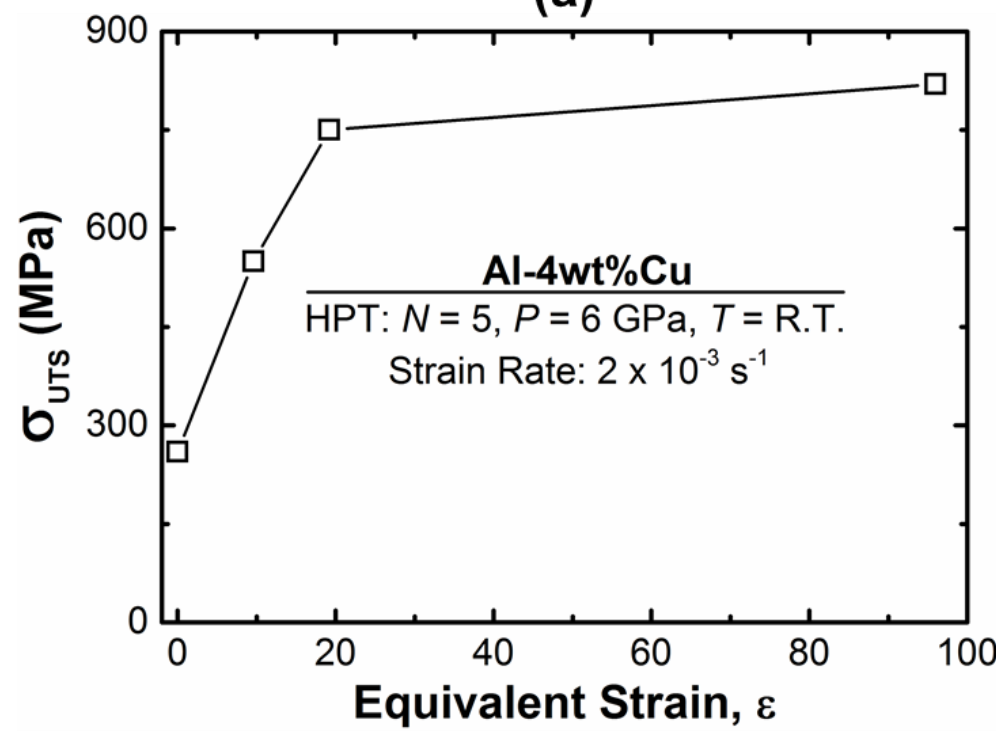

(b)

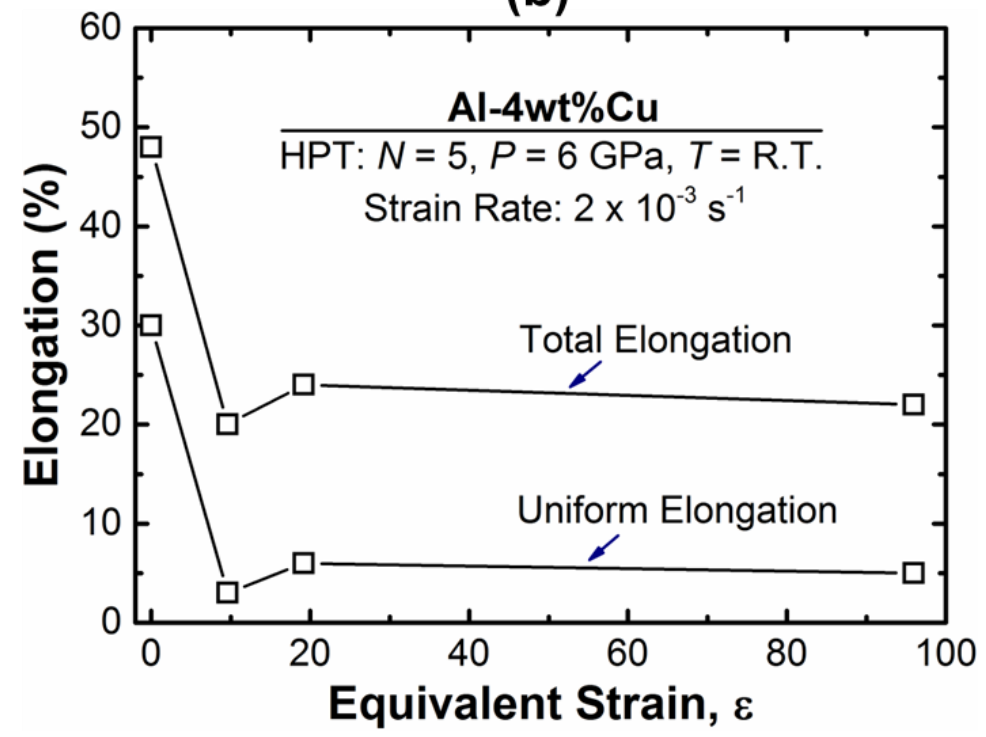

Figure 4 Variation of (a) ultimate tensile strength, (b) uniform elongation and total elongation to failure with equivalent strain for samples processed by HPT after various turns. 


\subsection{Mechanical properties after aging}

Figure 5 shows the hardness variation with aging time for the samples processed by solution treatment and by HPT processing for 5 turns and subsequently aged at room temperature and $353 \mathrm{~K}$. An increase in the hardness occurs not only for the solution-treated sample but also for the HPT-processed sample at both aging temperatures. However, the increase in hardness is much faster for the HPT-processed sample when compared to the solution-treated sample. Hardness peaks appear during the aging of HPT-processed samples while no hardness peak is reached during the aging of solution-treated samples. When the HPT-processed sample is aged at room temperature and $353 \mathrm{~K}$, the aging time for the occurrence of hardness peak is 5 min and 1.4 days, respectively. This suggests that the thermal stability of HPT-processed samples is unsatisfactory because of fast precipitation.

It was reported earlier that the precipitation kinetics in the coarse-grained $\mathrm{Al}-\mathrm{Cu}$ alloy is so slow [32]. However, it was shown that the SPD processing promotes the precipitation process because of increasing the diffusion coefficient $[33,34]$. It was also reported that the aging is accelerated in $\mathrm{Al}$ composites [35] and $\mathrm{Al}$ alloys [36] because of faster segregation of elements through the dislocation cores. It is also known that the nucleation and growth of precipitates may progress much faster when the dislocation density is high [35] or when the grain size is small [37]. Similar justifications may be employed to explain the fast aging behaviour of the current HPT-processed Al-Cu alloy because of high density of dislocations 
[38-42], large fraction of grain boundaries [2-6] and fast diffusion of atoms [43-49].

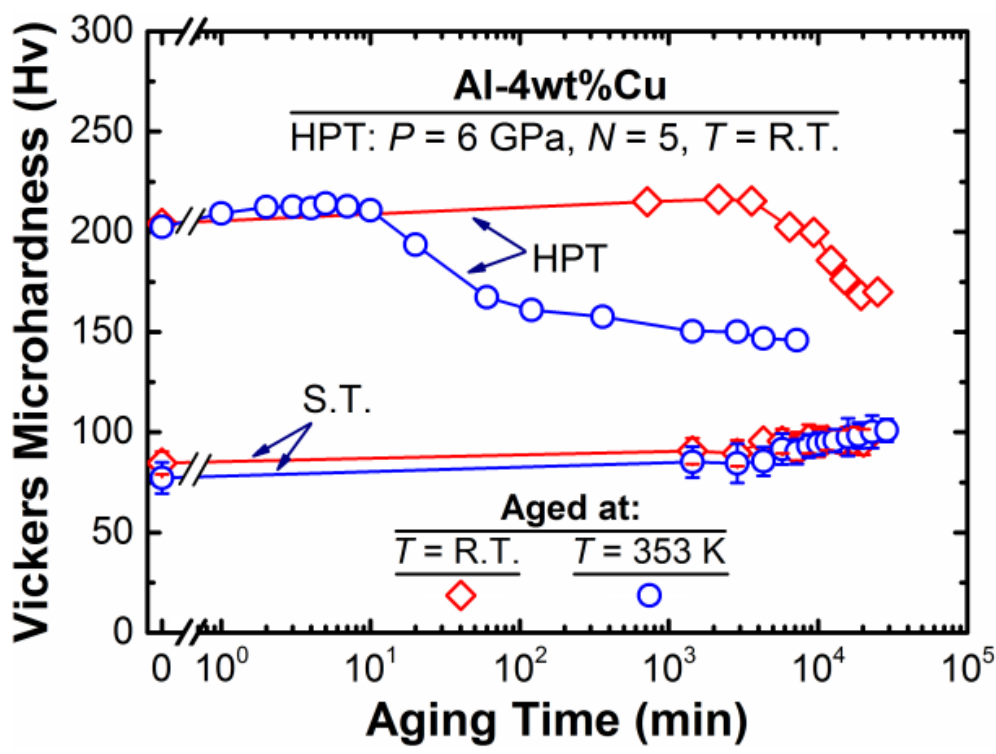

Figure 5 Variation of hardness with aging time for samples processed by solution treatment and HPT after 5 turns.

Figure 6 shows the stress-strain curves after tensile testing of the samples processed by HPT for 5 turns and subsequently aged at $353 \mathrm{~K}$ for various periods of time. The yield strength increases after aging for 5 min (peak age) when compared to the HPT-processed sample, but the tensile strength decreases with further increasing the aging time (over age). The variation of tensile strength with the aging time is in good agreement with the variation of hardness against the aging time, as shown in Fig. 5. The tensile ductility decreases significantly after the aging for $5 \mathrm{~min}$, but the ductility improves with further increase in the aging time. 


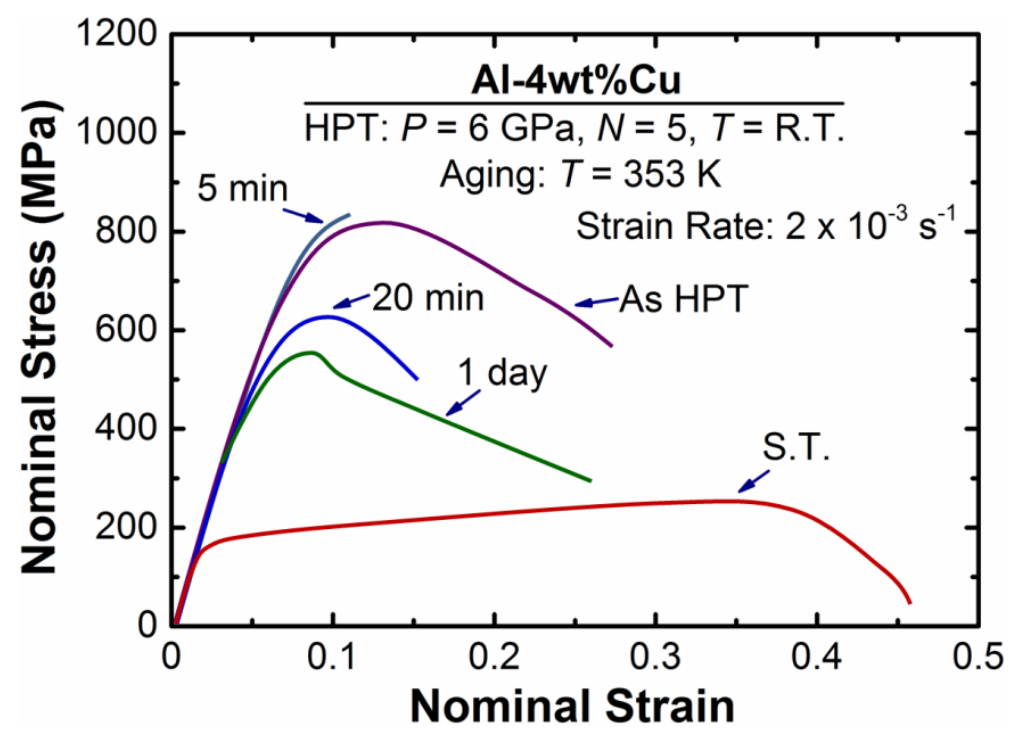

Figure 6 Nominal stress versus nominal strain curves for samples processed by HPT for 5 turns and subsequently aged at $353 \mathrm{~K}$ for various periods of time.

\subsection{Microstructures}

Figure 7 shows TEM bright-field images, dark-field images and the corresponding SAED patterns for (a) the sample processed by HPT for 5 turns and for the same sample after aging at $353 \mathrm{~K}$ for (b) $5 \mathrm{~min}$ (peak age), (c) $20 \mathrm{~min}$ (over age) and (d) 5 days (over age). Note that the microstructures in Fig. 7 correspond to the steady state in the plot of hardness against equivalent strain shown in Fig. 2(b). The microstructure after the HPT processing consists of small grains with an average grain size of $210 \pm 90 \mathrm{~nm}$. As evident from the SAED analysis with ring-shape patterns, the small grains should have high angles of misorientation. Close examination of the TEM micrographs reveals that no contrast related to precipitates is visible within the microstructure, but many dislocations are visible within the grains. The average 
grain size of $\sim 210 \mathrm{~nm}$ achieved for the current $\mathrm{Al}-\mathrm{Cu}$ alloy is one order of magnitude smaller than the grain size in HPT-processed pure $\mathrm{Al}$ [11-16] because the $\mathrm{Cu}$ atoms pin the movement of dislocations [5,11].
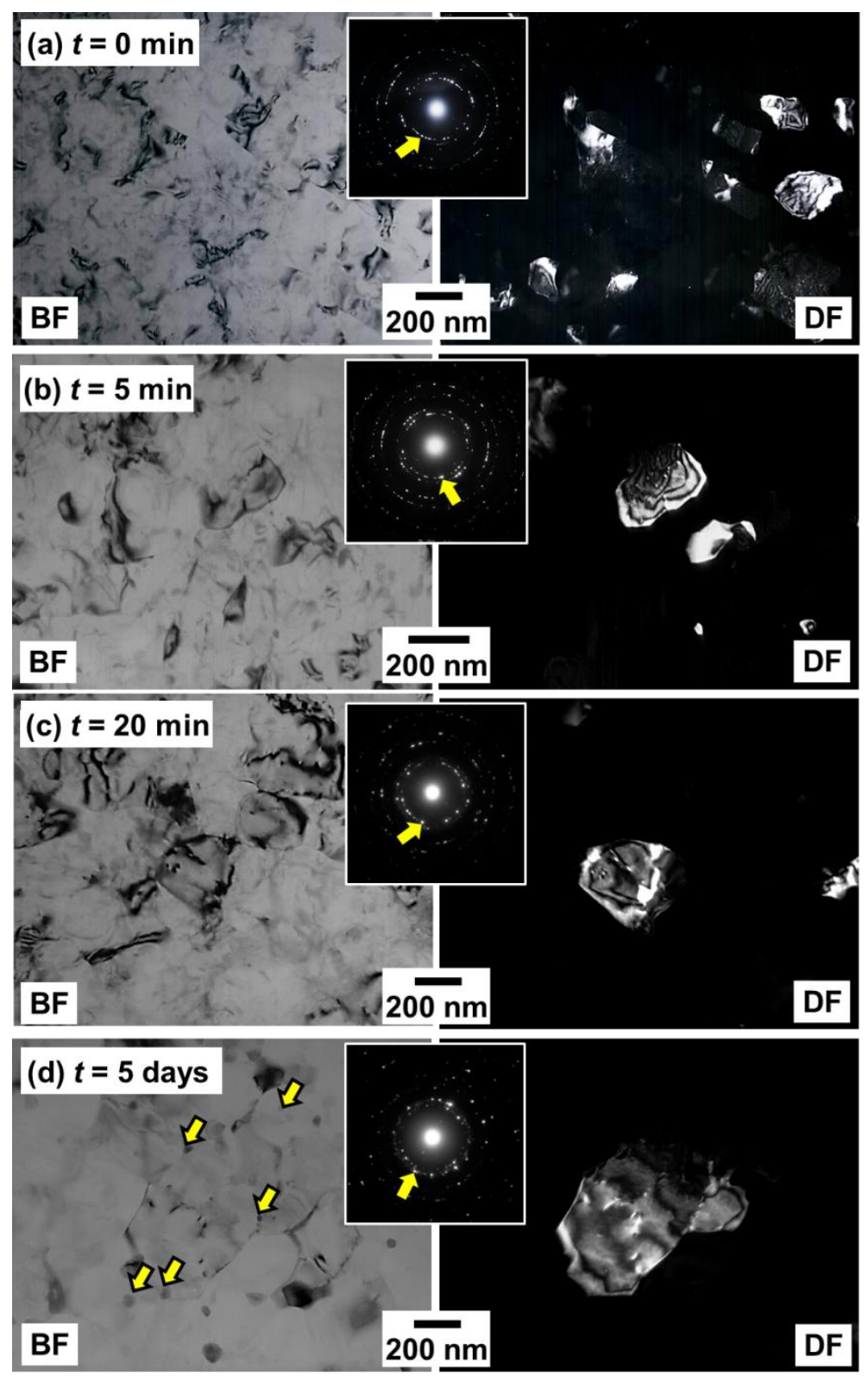

Figure 7 TEM bright-field images (left), dark-field images (right) and corresponding SAED patterns for samples processed by HPT for 5 turns and subsequently aged at $353 \mathrm{~K}$ for (a) $t=0$, (b) $t=5 \mathrm{~min}$, (c) $t=20 \min$ and (d) $t=5$ days. 
The grain size remains small and unchanged after 5 min as shown in Fig. 7(b), but no extra diffracted sports for precipitates are visible because of either insufficient fraction of the precipitates or their small sizes. The grain size increases to $\sim 260 \mathrm{~nm}$ and $\sim 390 \mathrm{~nm}$ by increasing the aging time to $20 \mathrm{~min}$ and 5 days, respectively, and many precipitates are now visible in the microstructure. The variation of grain size with the aging time is shown more clearly in Fig. 8.

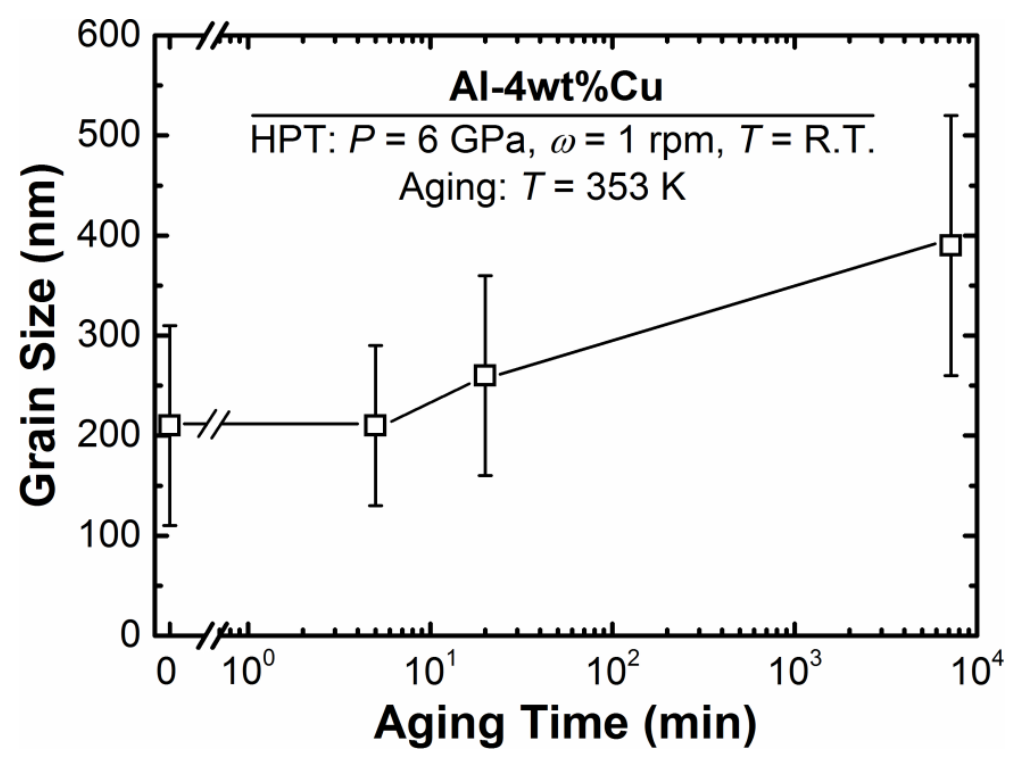

Figure 8 Variation of grain size with aging time for samples processed by HPT after 5 turns and subsequently aged at $353 \mathrm{~K}$.

The average size of precipitates appears to be $\sim 20 \mathrm{~nm}$ after aging for $20 \mathrm{~min}$, but the size of precipitates increases to $\sim 40 \mathrm{~nm}$ by prolonged aging for 5 days. Detailed examination of the sample aged for 5 days indicates that there are many spherical precipitates of $\mathrm{Al}_{2} \mathrm{Cu}$ in 
the interior of grains as well as along the grain boundaries, as shown by arrows in micrographs of Figs. 7(d) and 9. It should be noted that the diffracted beam selected for taking the dark-field image in Fig. 9 corresponds to the (110) plane of the $\mathrm{Al}_{2} \mathrm{Cu}$ phase.

\subsection{Phase transformations}

XRD profiles for the solution-treated sample, sample after the HPT processing for 5 turns and samples processed for 5 turns and subjected to subsequent aging at $353 \mathrm{~K}$ for $5 \mathrm{~min}$, 20 min, 120 min and 5 days are shown in Fig. 10. Formation of $\mathrm{Al}_{2} \mathrm{Cu}$ phase cannot be detected after the HPT processing or at the early stages of aging for $5 \mathrm{~min}$ within the sensitivity limits of the current XRD experiments, although the hardness increase suggests the formation of fine precipitates. Peaks for the $\mathrm{Al}_{2} \mathrm{Cu}$ phase appreciably appears after aging for 20 min, 120 min and 5 days in accordance with the TEM observations. A comparison between the peaks for $\mathrm{Al}$ and the peaks for $\mathrm{Al}_{2} \mathrm{Cu}$ indicates that the fraction of $\mathrm{Al}_{2} \mathrm{Cu}$ phase increases with increasing the aging time. 


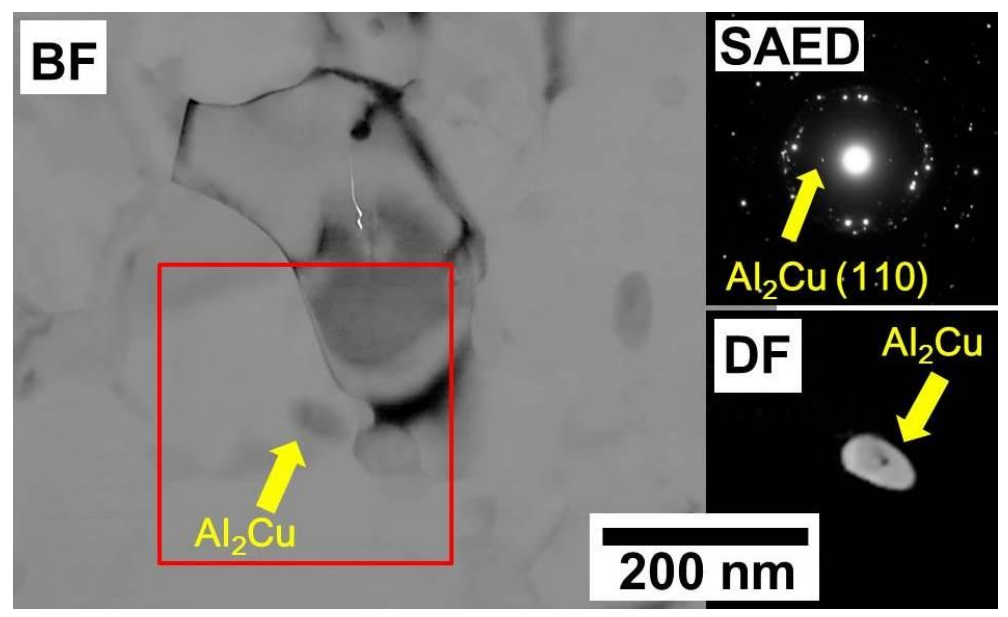

Figure 9 TEM bright-field image, corresponding SAED pattern and dark-field image taken from square region in bright-field image using diffracted beam corresponding to $\mathrm{Al}_{2} \mathrm{Cu}$ phase for sample processed by HPT for 5 turns and subsequently aged at $353 \mathrm{~K}$ for 5 days.

\subsection{Dislocation density}

Figure 10 shows that a significant peak broadening occurs by HPT processing when compared to the solution-treated sample. The peak broadening becomes less significant after the subsequent aging at $353 \mathrm{~K}$. This indicates unambiguously that the dislocations are generated and lattice strain increases during the HPT processing, while recovery of dislocations occurs during the post-HPT aging. The lattice strain, crystallite size and the dislocation density can be calculated from the peak broadening using the Williamson-Hall method [50]:

$$
\frac{\beta \cos \theta}{\lambda}=\frac{0.9}{D}+\frac{2 \varepsilon \sin \theta}{\lambda}
$$




$$
\rho=14.4 \frac{\varepsilon^{2}}{b^{2}}
$$

where $\beta$ is the full width at half maximum in $\operatorname{rad}, \lambda$ is the wavelength of $\mathrm{X}$-ray beam $(0.1542$ $\mathrm{nm}$ for $\mathrm{Cu} \mathrm{K} \alpha$ ), $D$ is the crystallite size, $\varepsilon$ is the lattice strain, $\theta$ is the Bragg angle, $\rho$ is the dislocation density and $b$ is the Burgers vector $(0.286 \mathrm{~nm}$ for $\mathrm{Al})$. By plotting $(\beta \cos \theta) / \lambda$ against $\sin \theta / \lambda$, the slope of the graph gives $2 \varepsilon$, the Y-intercept gives $0.9 / D$ and $\rho$ is calculated using Eq. (3).

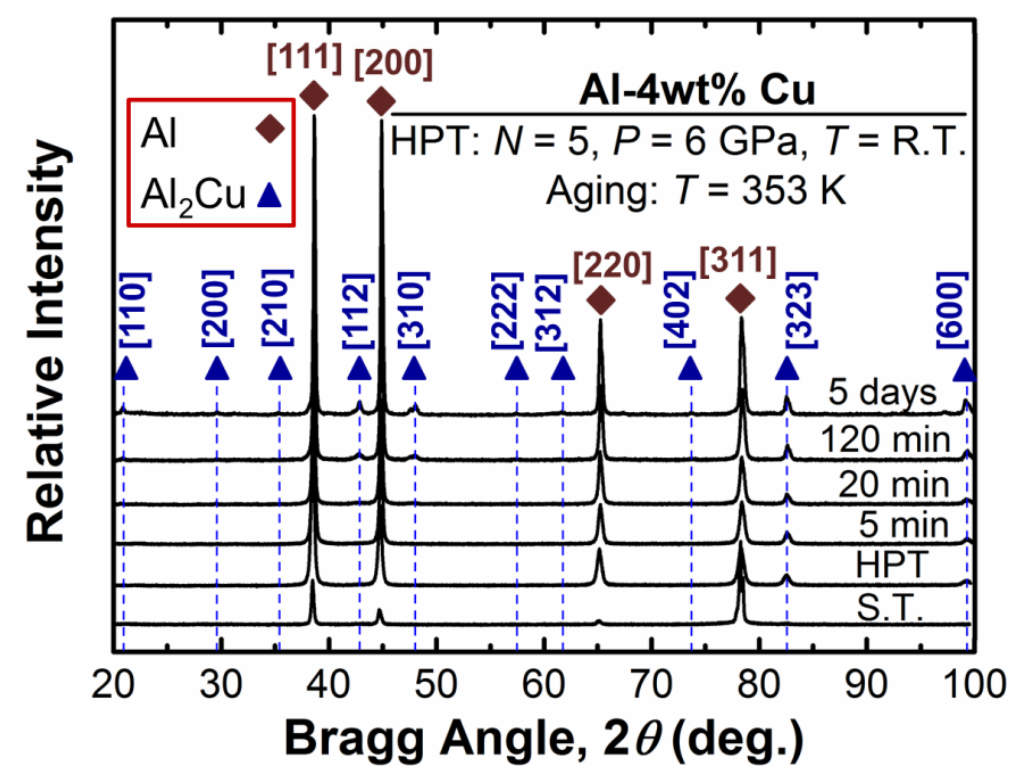

Figure $10 \quad$ XRD profiles for samples processed by solution treatment, HPT for 5 turns and post HPT-aging at $353 \mathrm{~K}$ for various periods of time.

The variation of dislocation density with the aging time is shown in Figs. 11 for the samples after HPT processing for 5 turns and subsequent aging at $353 \mathrm{~K}$. It is apparent that the dislocation density is $\sim 1.3 \times 10^{14}$ after the HPT processing and it decreases with increasing the aging time. This indicates that recovery should have occurred during the aging process. 


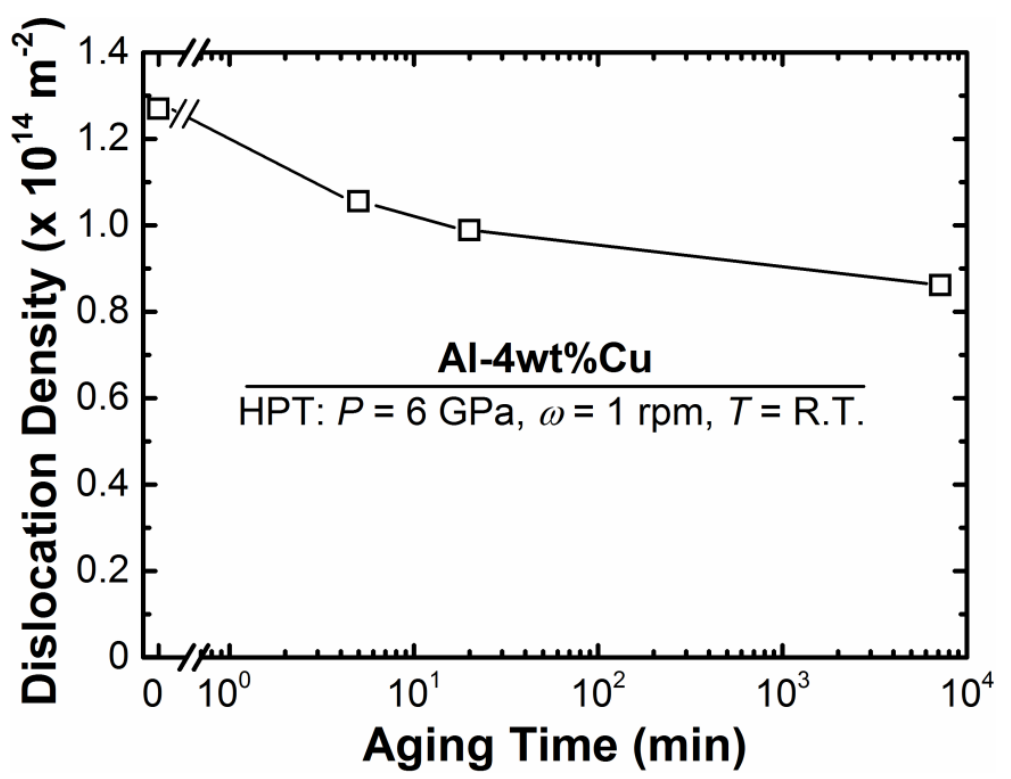

Figure 11 Variation of dislocation density, measured by Williamson-Hall method, against aging time for samples processed by HPT after 5 turns and subsequently aged at $353 \mathrm{~K}$.

\section{Discussion}

The current investigation demonstrates that the microstructural changes by HPT processing and post-HPT aging significantly influence the strength and hardness of the Al-Cu alloy. Several strengthening mechanisms can influence the hardness of age-hardenable Al-Cu alloys: solid-solution hardening $\Delta H_{S S}$, grain-boundary hardening $\Delta H_{G B}$, dislocation hardening $\Delta H_{D i s}$ and precipitation hardening $\Delta H_{P}$. When different hardening mechanisms are present, the total hardness is calculated by a superposition law as [51]:

$$
\Delta H V_{\text {Total }}=H V_{0}+\Delta H V_{S S}+\left(\Delta H V_{G B}^{n}+\Delta H V^{n}{ }_{D i s}+\Delta H V_{P}^{n}\right)^{1 / n}
$$

where $n$ has a value between 1 and 2 and $H V_{0}$ represents the hardness of coarse-grained pure 
metal with low dislocation density $(20 \mathrm{Hv}$ for annealed Al with a purity level of $99.999 \%$ [13]). Here, we assume $n=1$, which results in the following linear relationship:

$$
\Delta H V_{\text {Total }}=H V_{0}+\Delta H V_{S S}+\Delta H V_{G B}+\Delta H V_{\text {Dis }}+\Delta H V_{P}
$$

Quantitative estimation for the contribution of each hardening mechanism to the total hardness is given in Table 1 and details of the calculation are described below.

Table 1 Estimated contribution of different hardening mechanisms in comparison with experimental measurements for samples processed by HPT after 5 turns and subsequently aged at $353 \mathrm{~K}$ (all values are in $\mathrm{Hv}$ ).

\begin{tabular}{lllll}
\hline & \multicolumn{5}{c}{ Post-HPT Aging time } \\
\cline { 2 - 5 } & \multicolumn{1}{c}{$\mathbf{0}$} & \multicolumn{5}{c}{$\mathbf{5}$ min } & 20 min & \multicolumn{1}{c}{ 5 days } \\
\cline { 2 - 5 }$H V_{0}$ & 20 & 20 & 20 & 20 \\
$\Delta H V_{S S}$ & $4.2-7$ & $4.2-7$ & $4.2-7$ & $4.2-7$ \\
$\Delta H V_{G B}$ & 86 & 86 & 78 & 64 \\
$\Delta H V_{\text {Dis }}$ & 16 & 14 & 14 & 13 \\
$\Delta H V_{P}$ & unknown & unknown & 52 & 51 \\
$H V_{\text {Total }}$ & $>131$ & $>129$ & $<171$ & $<155$ \\
$H V_{\text {Measured }}$ & 205 & 214 & 190 & 146 \\
\hline
\end{tabular}

\subsection{Solid solution hardening}

The Fleischer model and the Labusch model for solid solution hardening are given by Eqs. (6) and (7), respectively [19,20]:

$$
\begin{gathered}
\Delta \tau_{S S}=\frac{G\left|\varepsilon_{G}^{\prime}{ }_{G}-m \varepsilon_{b}\right|^{3 / 2} c^{1 / 2}}{\alpha} \\
\Delta \tau_{S S}=\frac{G\left[{\left.\varepsilon^{\prime}{ }_{G}{ }^{2}+\left(15 \varepsilon_{b}\right)^{2}\right]^{2 / 3} c^{2 / 3}}_{\varphi}\right.}{}
\end{gathered}
$$


In these two models, $\Delta \tau_{S S}$ is the increase in shear stress due to solution hardening, which can be converted to normal stress using a Taylor factor of $\sim 3$ and to the hardness by a factor of $\sim 9$, $G$ is the shear modulus (26 GPa for the Al-Cu alloy [11]), $c$ is the atomic fraction of solute atoms ( 0.017 in this study), $m=3$ for movement of screw dislocations, $\alpha=700$ and $\varphi=550$ for fcc metals, $\varepsilon_{b}=(\mathrm{d} b / \mathrm{d} c) / b$ is the atomic size mismatch $\left(\varepsilon_{b}=-0.124\right.$ in this study [11] $)$ and $\varepsilon_{G=}^{\prime} \varepsilon_{G} /\left(1+\varepsilon_{G}\right)$, where $\varepsilon_{G}=(\mathrm{d} G / \mathrm{d} c) / G$ is the modulus mismatch $\left(\varepsilon_{G}=0.831\right.$ in this study [11]). If all atoms of $\mathrm{Cu}$ are assumed be present in the solid solution form, the contribution of solid solution hardening is estimated as $\Delta H_{S S}=4.2 \mathrm{Hv}$ and $7 \mathrm{Hv}$ using the Fleischer model and the Labusch model, respectively.

\subsection{Grain boundary hardening}

The Hall-Petch relationship for the grain boundary strengthening is usually described by $[17,18]$ :

$$
\Delta \sigma_{G B}=\sigma_{y}-\sigma_{0}=\frac{k_{y}}{\sqrt{d}}
$$

where $\Delta \sigma_{G B}$ is the increase in normal stress due to grain boundary hardening, $\sigma_{y}$ is the Hall-Petch strength, $d$ is the average grain size (given in Fig. 8), $\sigma_{0}$ is the friction stress (170 $\mathrm{MPa}$ for the Al-Cu alloy [52]) and $k_{\mathrm{y}}$ is the Hall-Petch slope $\left(0.13 \mathrm{MNm}^{-3 / 2}\right.$ for the Al-Cu alloy [52]). Considering that the average grain sizes are $210 \mathrm{~nm}$ after the HPT processing and $\sim 210 \mathrm{~nm}, \sim 260 \mathrm{~nm}$ and $\sim 390 \mathrm{~nm}$ after the post-HPT aging at $353 \mathrm{~K}$ for $5 \mathrm{~min}, 20 \mathrm{~min}$ and 
5 days, an estimation results in grain boundary hardening values of $\Delta H_{G B}=86 \mathrm{Hv}, 86 \mathrm{Hv}, 78$ $\mathrm{Hv}$ and $64 \mathrm{Hv}$, respectively.

\subsection{Dislocation hardening}

The Bailey-Hirsch relationship is adopted in the current study to evaluate the strengthening by accumulation of dislocations [19]:

$$
\Delta \tau_{D i s}=\alpha^{\prime} G b \sqrt{\rho}
$$

where $\Delta \tau_{D i s}$ is the increase in shear stress due to dislocation hardening and $\alpha^{\prime}=0.2$ for fcc metals. If the dislocation densities given in Fig. 11 are used for calculations, the hardness increase by dislocations accumulation can be estimated as $\Delta H V_{D i s}=16 \mathrm{Hv}$ after the HPT processing and $14 \mathrm{Hv}, 14 \mathrm{Hv}$ and $13 \mathrm{Hv}$ after the post-HPT aging at $353 \mathrm{~K}$ for $5 \mathrm{~min}, 20 \mathrm{~min}$ and 5 days, respectively.

\subsection{Precipitation hardening}

To estimate the hardening by precipitates, the following Orowan equation is employed [53]:

$$
\Delta \tau_{P}=\frac{G b}{\lambda^{\prime}}
$$

where $\Delta \tau_{P}$ is the increase in shear stress due to precipitation hardening and $\lambda^{\prime}=L-d_{P}$ is the inter-particle spacing, where $L$ is the distance between particles and $d_{\mathrm{P}}$ is the size of particles. 
In this study, precipitates were unable to be detected after the HPT processing as well as after the post-HPT aging at $353 \mathrm{~K}$ for $5 \mathrm{~min}$ within the sensitivity limits of XRD and conventional TEM, but the precipitates were detected by prolong aging. The average size of precipitates was measured as $d_{\mathrm{P}}=\sim 20 \mathrm{~nm}$ and $\sim 40 \mathrm{~nm}$ after aging for $20 \mathrm{~min}$ and 5 days, respectively, and the average distance between the particles was estimated as $L=\sim 150 \mathrm{~nm}$ and $\sim 175 \mathrm{~nm}$ after aging for $20 \mathrm{~min}$ and 5 days, respectively. Therefore, the precipitation hardening is calculated as $\Delta H V_{D i s}=52 \mathrm{Hv}$ and $51 \mathrm{Hv}$ after the post-HPT aging for $20 \mathrm{~min}$ and 5 days, respectively.

\subsection{Total hardening by different mechanisms}

As compared in Table 1, the total hardening calculated through the four different hardening mechanisms is reasonably consistent with the experimental measurements for the samples processed by HPT and subsequently aged at $353 \mathrm{~K}$ for $20 \mathrm{~min}$ and 5 days. However, the calculated values are significantly smaller than the experimental measurements for the as-HPT-processed samples as well as for the sample after post-HPT aging at $353 \mathrm{~K}$ for $5 \mathrm{~min}$. Such significant differences suggest that some kinds of fine precipitates should have formed during HPT processing as well as subsequent aging for $5 \mathrm{~min}$, although detection of precipitates was failed in this study within the sensitivity limits of XRD and conventional TEM. An earlier study using high resolution TEM confirmed the formation of different intermetallic phases such as $\mathrm{Al}_{2} \mathrm{Cu}, \mathrm{AlCu}$ and $\mathrm{Al}_{4} \mathrm{Cu}_{9}$ in the $\mathrm{Al}-\mathrm{Cu}$ system during $\mathrm{HPT}$ 
processing [49]. It should be noted that in addition to stable intermetallic phases, other metastable phases (Guinier-Preston (GP) zones, $\theta$ " and $\theta^{\prime}$ phases) are formed in the Al-Cu alloys [54-56].

Some studies reported that the Fleischer equation should be modified for the solution hardening in the nanograined metals [57]. Several publications also reported that the Hall-Petch relationship may break down with a positive or negative deviation in UFG metals [58-60]. Moreover, it was reported that the effect of dislocations on the hardening may be different in the UFG materials when compared to their coarse-grained counterparts [61]. Despite these reports, the consistency between the calculated hardness levels and the experimentally measured levels for the samples processed by HPT and subsequently aged at $353 \mathrm{~K}$ for $20 \mathrm{~min}$ and 5 days suggest that the classic hardening equations are still applicable to the current UFG Al-Cu alloy.

The analyses summarized in Table 1 unambiguously indicate that the combination of different strengthening mechanisms is quite effective to improve the strength of HPT-processed materials beyond the saturation levels. The grain boundary hardening and the precipitation hardening appear to be the most effective mechanisms to increase the strength of the Al-Cu alloy, whereas the contribution of solid solution hardening and the dislocation hardening to the total hardness is minor as less than $10 \%$. Earlier publications also suggested that the grain boundaries have the largest contribution to the hardening in many 
HPT-processed pure metals and alloys $[11,12]$. The large contribution of precipitates to the hardening was reported in several papers $[22,27]$. Several publications suggested that the dislocations have the largest contribution to the hardening [37-39,62]. The contribution of solid-solution hardening in UFG alloys is small and usually less than $15 \%$ [11].

\section{Conclusions}

The microstructures, mechanical properties and formation of precipitates were investigated in an $\mathrm{Al}-\mathrm{Cu}$ alloy after high-pressure torsion (HPT) processing and after post-HPT aging at $353 \mathrm{~K}$. The contribution of different hardening mechanisms (solid solution hardening, grain boundary hardening, dislocation hardening, and precipitation hardening) were quantitatively evaluated for different processing conditions.

1. Hardness increases with strain and saturates to a steady-state level as $205 \mathrm{Hv}$ after HPT processing, while the grain size is reduced to $\sim 210 \mathrm{~nm}$ at the steady state.

2. Age hardening occurs after aging of the HPT-processed sample at room temperature and $353 \mathrm{~K}$ and $\mathrm{Al}_{2} \mathrm{Cu}$ particles precipitate.

3. The HPT-processed Al-Cu alloy exhibits weak thermal stability. The material exhibits a softening behavior within a few days after storage at room temperature and within a few minutes after aging at $353 \mathrm{~K}$.

4. Dislocation recovery occurs after aging for short time while grain growth occurs by 
prolong aging for a few days although the grain size is kept well within the submicrometer range.

5. The strengthening by grain boundaries and precipitates are the dominant strengthening mechanism, while the contribution of strengthening by solid solution and dislocations accumulation is less than $10 \%$.

\section{Acknowledgements}

One of the authors (IFM) gratefully acknowledges SIRIM Berhad, Malaysia for a scholarship. KE thanks the Japan Society for Promotion of Science (JSPS) for a Grant-in-Aid for Research Activity (No. 25889043). This work was supported in part by Japan Science and Technology Agency (JST) under Collaborative Research Based on Industrial Demand "Heterogeneous Structure Control: Towards Innovative Development of Metallic Structural Materials", in part by the Light Metals Educational Foundation of Japan, and in part by a Grant-in-Aid for Scientific Research from the MEXT, Japan, in Innovative Areas "Bulk Nanostructured Metals" (no. 22102004). 


\section{References}

[1] P.W. Bridgman, Phys. Rev. 48 (1935) 825-847.

[2] R.Z. Valiev, R.K. Islamgaliev, I.V. Alexandrov, Prog. Mater. Sci. 45 (2000) 103-189.

[3] R.Z. Valiev, Y. Estrin, Z. Horita, T.G. Langdon, M.J. Zehetbauer, Y.T. Zhu, JOM 58 (4) (2006) 33-39.

[4] A.P. Zhilyaev, T.G. Langdon, Prog. Mater. Sci. 53 (2008) 893-979.

[5] R. Pippan, S. Scheriau, A. Taylor, M. Hafok, A. Hohenwarter, A. Bachmaier, Annu. Rev. Mater. Res. 40 (2010) 319-343.

[6] Y. Estrin, A. Vinogradov, Acta Mater. 61 (2013) 782-817.

[8] A. Vorhauer, R. Pippan, Scripta Mater. 51 (2004) 921-925.

[7] G. Sakai, Z. Horita, T.G. Langdon, Mater. Sci. Eng. A 393 (2005) 344-351.

[8] A.P. Zhilyaev, K. Oh-ishi, T.G. Langdon. T.R. McNelley, Mater. Sci. Eng. A 42 (2007) $1517-1528$

[9] M.T. Perez-Prado, A.A. Gimazov, O.A. Ruano, M.E. Kassnerc, A.P. Zhilyaev, Scripta Mater. 58 (2008) 219-222.

[10] A. Loucif, R.B. Figueiredo, T. Baudin, F. Brisset, R. Chemam, T.G. Langdon, Mater. Sci. Eng. A 532 (2012) 139-145.

[11] K. Edalati, D. Akama, A. Nishio, S. Lee, Y. Yonenaga, J.M. Cubero-sesin, Z. Horita, Acta Mater. 69 (2014) 68-77.

[12] K. Edalati, Z. Horita, Acta Mater. 59 (2011) 6831-6836.

[13] K. Edalati, J.M. Cubero-Sesin, A. Alhamidi, I.F. Mohamed, Z. Horita, Mater. Sci. Eng. A 613 (2014) 103-110.

[14] C. Xu, Z. Horita, T.G. Langdon, Acta Mater. 56 (2008) 5168-5176.

[15] M. Kawasaki, B. Ahn, T.G. Langdon, J. Mater. Sci. 45 (2010) 4583-4593.

[16] M. Kawasaki, R.B. Figueiredo, T.G. Langdon, Acta Mater. 59 (2011) 308-316.

[17] E.O. Hall, Proc. Phys. Soc. B 64 (1951) 747-753. 
[18] N.J. Petch, J. Iron Steel Inst. 174 (1953) 25-28.

[19] J.E. Bailey, P.B. Hirsch, Philos. Mag. 5 (1960) 485-497.

[20] R.L. Fleischer, Acta Metall. 11 (1963) 203-209.

[21] R. Labusch, Acta Metall. 20 (1972) 917-927.

[22] Y.H. Zhao, X.Z. Liao, Z. Jin, R.Z. Valiev, Y.T. Zhu, Acta Mater. 52 (2004) 4589-4599.

[23] Z. Horita, K. Ohashi, T. Fujita, K. Kaneko, T.G. Langdon, Adv. Mater. 17 (2005) $1599-1602$

[24] K. Ohashi, T. Fujita. K. Kaneko. Z. Horita, T.G. Langdon, Mater. Sci. Eng. A 437 (2006) 240-247.

[25] S. Lee, Z. Horita, S. Hirosawa, K. Matsuda, Mater. Sci. Eng. A 546 (2012) 82-89.

[26] S. Lee, Z. Horita, Metall. Mater. Trans. A 44 (2013) 3221-3231.

[27] K. Ma, H. Wen, T. Hu, T.D. Topping, D. Isheim, D.N. Seidman, E.J. Lavernia, J.M. Schoenung, Acta Mater. 62 (2014) 141-155.

[28] J. Kaneko, J. JILM 27 (1977) 384-390.

[29] A. Cerri, P. Leo, Mater. Sci. Eng. A 226 (2005) 410-411.

[30] T. Masuda, S. Hirosawa, Z. Horita, K. Matsuda, J. JILM 75 (2011) 283-290.

[31] K. Edalati, T. Fujioka, Z. Horita, Mater. Sci. Eng. A 497 (2008) 168-173.

[32] J.M. Silcock, T.J. Heal, H.K. Hardy, J. Ins. Metals 82 (1953-1954) 239-248.

[33] J. Gubicza, I. Schiller, N.Q. Chinh, I. Illy, Z. Horita, T.G. Langdon, Mater. Sci. Eng. A 460-461 (2007) 77-85.

[34] W.J. Kim, C.S. Chung, D.S. Ma, S.I. Hong, H.K. Kim, Scripta Mater. 49 (2003) $333-338$.

[35] S.I. Hong, G.T. Gray, Acta Metall. Mater. 40 (1992) 3299-3315.

[36] G. Sha, Y.B. Wang, X.Z. Liao, Z.C. Duan, S.P. Ringer, T.G. Langdon, Acta Mater. 57 (2009) 3123-3132.

[37] S. Mazzini, J.C. Caretti, Scripta Metall. Mater. 25 (1991) 1987-1990. 
[38] M.J. Starink, X.C. Cheng, S. Yang, Acta Mater. 61 (2013) 183-192.

[39] J. Gubicza, N.Q. Chinh, J.L. Labar, S. Dobatkin, Z. Hegedus, T.G. Langdon, J. Alloys Compd. 483 (2009) 271-274.

[40] X.G. Qiao, M.J. Starink, N. Gao, Mater. Sci. Eng. A 513-514 (2009) 52-58.

[41] E.Y. Yoon, D.J. Lee, T.S. Kim, H.J. Chae, P. Jenei, J. Gubicza, T. Ungar, M. Janecek, J. Vratna, S. Lee, H.S. Kim, J. Mater. Sci. 47 (2012) 7117-7123.

[42] D.H. Ahn, H.S. Kim, Y. Estrin, Scripta Mater. 67 (2012) 121-124.

[43] T. Fujita, Z. Horita, T.G. Langdon, Philos. Mag. A 82 (2002) 2249-2262.

[44] T. Fujita, Z. Horita, T.G. Langdon, Mater. Sci. Eng. A 271 (2004) 241-250.

[45] X. Sauvage, P. Jessner, F. Vurpillot, R. Pippan, Scripta Mater. 58 (2008) 1125-1128.

[46] S.V. Divinski, J. Ribbe, D. Baither, G. Schmitz, G. Reglitz, H. Rosner, K. Sato, Y. Estrin, G. Wilde, Acta Mater. 57 (2009) 5706-5717.

[47] S.V. Divinski, G. Reglitz, H. Rosner, Y. Estrin, G. Wilde, Acta Mater. 59 (2011) 1974-1985.

[48] B.B. Straumal, A.A. Mazilkin, B. Baretzky, G. Schutz, E. Rabkin, R.Z. Valiev, Mater. Trans. 53 (2012) 63-71.

[49] K. Oh-ishi, K. Edalati, H.S. Kim, K. Hono, Z. Horita, Acta Mater. 61 (2013) 3482-3489.

[50] G.K. Williamson, W.H. Hall, Acta Metall. 1 (1953) 22-31.

[51] U.F. Kocks, A.S. Argon, M.F. Ashby, Prog. Mater. Sci.19 (1975) 1-288.

[52] T. Shanmugasundaram, M. Heilmaier, B.S. Murty, V.S. Sarma, Mater. Sci. Eng. A 527 (2010) 7821-7825.

[53] E. Orowan, Symposium on Internal Stresses in Metals and Alloys (Institute of Metal, London, 1947) 451-453.

[54] A. Guinier, Nature 142 (1938) 569-570.

[55] G.D. Preston, Nature 142 (1938) 570-570.

[56] R.B. Nicholson, J.J. Nutting, Philos. Mag. 3 (1958) 531-535. 
[57] T.J. Rupert, J.C. Trenkle, C.A. Schuh, Acta Metall. 59 (2011) 1619-1631.

[58] C.S. Pande, K.P. Cooper, Prog. Mater. Sci. 54 (2009) 689-706.

[59] N. Kamikawa, X. Huang, N. Tsuji, N. Hansen, Acta Mater. 57 (2009) 4198-4208.

[60] M. Furukawa, Z. Horita, M. Nemoto, R.Z. Valiev, T.G. Langdon, Acta Mater. 44 (1996) $4619-4629$.

[61] X. Huang, N. Hansen, N. Tsuji, Science 312-5771 (2006) 249-251.

[62] B. Joni, E. Schafler, M. Zehetbauer, G. Tichy, T. Ungar, Acta Mater. 61 (2014) 632-642.

Words:

5,334

Characters:

27,603 